\title{
Fotografia e saudade: três considerações sobre a perda
}

\section{Michel de Oliveira}

Doutorando do Programa de Pós-Graduação em Comunicação e Informação da Universidade Federal do Rio Grande do Sul (Porto Alegre, Brasil). Mestre em Comunicação e especialista em Fotografia: práxis e discurso, ambos pela Universidade Federal de Londrina. Bolsista da Coordenação de Aperfeiçoamento de Pessoal de Nível Superior (CAPES). E-mail:michel.os@hotmail.com.br
Resumo: $\mathrm{O}$ artigo discute a relação entre fotografia e saudade, a fim de observar como a imagem fixa mantém conexões com esse complexo sentimento. Para aprofundar a questão, apresenta apontamentos sobre as perdas que envolvem a fotografia: dos entes queridos que não mais existem - imortalizados nos retratos -, da materialidade da imagem e da vocação mnemônica atribuída aos registros da câmera. A partir desse exercício de reflexão, é possível depreender que a fotografia, em suas diversas fases e usos sociais, ainda preserva sua vocação elegíaca, a suscitar saudades.

Palavras-chave: Fotografia; Saudade; Memória; Cultura visual.

\section{Photography and nostalgia: three considerations about loss}

Abstract: The article discusses the relationship between photography and nostalgia, in order to observe how the still image maintains connections with this complex feeling. To deepen the question, it presents notes on the losses that involve photography: of loved ones who no longer exist - immortalized in portraits -, of the materiality of the image and of the mnemonic vocation attributed to the camera records. From this exercise of reflection, it is possible to realize that photography, in its various phases and social uses, still preserves its elegiac vocation, evoking nostalgia.

Keywords: Photography; Nostalgia; Memory; Visual culture. 


\section{Introdução}

${ }^{1}$ Relato feito a partir da visita à casa de dona Relindes Scholze Vaz, em junho de 2015, durante entrevista para a pesquisa que resultou na dissertação Saudades eternas: a fotografia no limiar entre a morte e a eternidade (SILVA, 2016).

\footnotetext{
${ }^{2}$ Tradução livre do original: "No caso da saudade non se trata dun eco sentimental de 'algo'; é un sentimento sen obxecto, un puro sentir, o decorrer espontâneo do sentimento ceibe de toda relación co pensamento ou coa vontade. De aí a súa escuridade, a súa incompreensibilidade conceptual".
}

Dona Relindes abre o armário e volta com alguns álbuns ${ }^{1}$. Inúmeras fotografias a preservar no papel tantas cenas do passado. Enquanto folheia as páginas encadernadas, narra histórias dos dias idos: festas em família, a infância dos filhos, animais de estimação, as reformas na casa, encontros com amigos, viagens de férias, os entes queridos que não mais vivem, os pés de couve maiores que o telhado.

Os retratos suscitam a tessitura feita com fragmentos, recordações permeadas por sentimentos e afetos. "Volta e meia eu pego esses retratos pra rever. A gente sente saudade... Mexe... Mexe..." (VAZ, 2015: 114'12"). A declaração de dona Relindes se apresenta como indício da complexa relação estabelecida entre fotografia e saudade. Ao ser tomada como registro mnemônico, a imagem fixa motiva sentimentos que excedem os limites do visível. A superfície bidimensional se desdobra, ganhando profundidade a partir do relato oral motivado pela fotografia.

Essas considerações iniciais apresentam alguns pontos que serão abordados na discussão aqui delineada, a qual tem como eixo condutor a relação entre fotografia e saudade. Trata-se de um exercício dialógico que busca apresentar a complexidade do sentimento saudoso - cuja dinâmica escapa às conceituações - e, ainda, estabelecer conexões com os usos sociais atribuídos à fotografia, tomada socialmente como relicário afetivo, principalmente no reduto doméstico.

O debate culmina na relação da saudade com a perda, a fim de estabelecer um entendimento mais complexo sobre os registros da câmera escura, observados a partir das transformações da fotografia ao longo de sua história e dos novos usos atribuídos às imagens fixas.

\section{Da complexidade do sentido à facilidade do sentir}

Que é a saudade? Por apresentar uma ontologia complexa, esse sentimento incógnito não se enquadra em definições. Da forma como é vivenciada no Brasil, a saudade é herança de Portugal. Isso motivou a criação de uma espécie de mitologia linguística, que defende a posse do termo para os falantes de português: os outros idiomas não têm tradução para saudade, costuma-se destacar. No entanto, Eduardo Lourenço (1999: 15) observa que esse sentimento é partilhado por outras culturas: "Sob outros nomes ou sem nomes, a saudade é universal não apenas como desejo de eternidade, mas como sensação e sentimento vividos da eternidade. Ela brilha sozinha no coração de todas as ausências".

O antropólogo Roberto DaMatta (1993) amplia essa compreensão ao defender que a saudade é um conceito duplo que parte do geral em direção ao particular. Ao se debruçar sobre as singularidades, o autor entrevê um componente antropológico que torna possível definir uma saudade luso-brasileira: "aprendemos a sentir saudade, como aprendemos a brincar carnaval e a comer feijoada" (DAMATTA, 1993: 23, grifo do autor).

Essa compreensão, no entanto, não responde à questão primordial: que é a saudade? A pergunta é quase retórica, pois se parte para a busca de respostas possíveis que não darão conta desse sentimento. Apesar de alguns debates já terem sido levantados, a saudade segue conservando certo ar de mistério. É como se existisse apenas para ser sentida, e não para ser definida. Ramón Piñeiro (1984) comenta sobre essa dificuldade de explicar o sentimento saudoso:

No caso da saudade não se trata do eco sentimental de "algo"; é um sentimento sem objeto, um puro sentir, o decorrer espontâneo do sentimento livre de toda relação com o pensamento ou com a vontade. Daí a sua escuridão, sua incompreensibilidade conceitual. (PIÑERO, 1984: 31) ${ }^{2}$ 
Eduardo Lourenço (1999) classifica a saudade como enigma. Talvez por isso tenha instigado mais poetas do que pesquisadores, os primeiros apresentando maior ímpeto diante das incógnitas. A subjetividade contida na compreensão desse sentimento pode ser um dos principais desafios para os acadêmicos, o que justifica a escassez de referenciais teóricos sobre o tema.

No ensaio Da saudade ao saudosismo, o escritor português Afonso Botelho defende que para compreender a saudade é necessário estabelecer ligações entre o pensamento racional e a subjetividade. Segundo o autor, "a saudade deve ter uma natureza supra-racional e, também por igual motivo, supra-afectiva, o que é o mesmo que dizer que nem só a razão nem só a afectividade determina o estado saudoso" (BOTELHO, 1990: 32).

O principal ponto de concordância entre os debatedores da saudade é a sua ligação com a ausência. Trata-se de um sentimento que se enraíza nos buracos deixados por aquilo que falta, seja pela distância ou pela extinção. "A saudade é antes de tudo, ausência, apartamento de pessoas, de seres livres que se perderam", reitera Botelho (1990: 36). Mas essa ausência só se faz sentir por estar envolvida com outro sentimento tão incógnito e indefinível quanto a saudade: o amor. Ainda segundo o autor, a saudade assegura a continuidade do amor: "Ela é, afinal, o próprio amor vagando na procela do tempo e do espaço" (Ibid.: 24).

Só faz falta aquilo que se ama. É na ausência dos entes queridos, da terra natal ou do aconchego do lar materno que os ventos da saudade sopram, remexendo sentimentos e trazendo à tona as velhas lembranças encobertas pela poeira do tempo. "Com a saudade, não recuperamos apenas o passado como paraíso; inventamo-lo" (LOURENÇO, 1999: 14, grifo do autor). Nesse aspecto, a saudade interage com a imaginação, que auxilia na rememoração afetiva trazendo aconchego e aplacando momentaneamente a ausência.

"O amor e a ausência são causa normal da saudade, mas não a origem necessária", afirma Botelho (1990: 139), e complementa: "o amor e o desejo fenecem e a saudade persiste". Com essa afirmação, o autor explicita que o sentimento saudoso é da ordem do duradouro, permanecendo até mesmo quando outros sentimentos considerados mais nobres se extinguem. A partir dessa compreensão, é possível aproximar a saudade das instâncias da morte - que aterroriza os vivos com sua ausência perpétua. É justamente a saudade, com seus paradoxos de dor e prazer, que aplaca a falta eterna deixada pelos que se foram.

Ao se apresentar como barreira contra o fluxo irremediável do tempo, a saudade embaralha as instâncias temporais. "Passado, presente e futuro encontram, portanto, a sua unidade dinâmica na dialética íntima da saudade" (Ibid: 162). Possivelmente em razão disso a saudade se apresente como sentimento confuso, que aparenta manter em suspensão o indivíduo saudosista. Observar um retrato antigo, reler uma velha carta ou entregar-se ao exercício mental da rememoração faz a experiência sensória se deslocar para um tempo único, que sobrepõe presente, passado e a noção de futuro.

Outra nuance da saudade é a ambiguidade: pode evocar sentimentos de dor e pesar ou, em contrapartida, suscitar sensações de prazer e conforto. Apesar dessa capacidade de mobilizar sensações distintas, Piñeiro (1984) ressalta que, em essência, a saudade não é nem triste, nem alegre, mas uma forma de sentir dentro dos limites da individualidade de cada sujeito. Segundo Botelho (1990: 31):

A saudade é causa de prazer, por intervenção activa da razão, que ilumina a memória e permite que se verifique quando o estado actual é melhor que a situação lembrada, e aquele em que, parte da razão pelo menos, se deixa afectar pelo rijo desejo de voltar ao estado ausente.

Em contraposição, a saudade pode evocar emoções negativas quando o indivíduo não consegue superar a falta do que suscitou a ausência ou a distância do 
${ }^{3}$ Tradução livre do original: "É a vivencia espontánea da pura intimidade do ser humano, vivencia fonda, escura e pasiva, porque se produce com independencia e con anterioridade á atividade do intelecto da vontade".

${ }^{4}$ Tradução livre do original: "Pois na saudade o home queda afundido dentro de si mesmo, illado de todo contacto exterior". que se ama. Nesse aspecto, o sentimento passa a flertar com a tristeza e com a melancolia. Mas enquanto os outros sentimentos são experimentados de forma passageira, a saudade "faz do 'passageiro' algo de idealmente presente" (LOURENÇO, 1999: 32).

Piñeiro (1984: 33) define a saudade como "sentimentalidade pura". Ao afirmar isso, o autor busca explicitar a relação que esse sentimento estabelece com a afetividade, e mais, deseja apresentar a saudade como a principal instância de subjetividade: "É a vivência espontânea da pura intimidade do ser humano, vivência profunda, escura e passiva, porque é produzida com independência e anterior à atividade do intelecto e da vontade"3 (Ibid.: 34).

Sentir saudade é, portanto, um exercício de autoconhecimento, por meio do qual é possível imergir na própria interioridade: "na saudade o homem fica afundado dentro de si mesmo, isolado de todo contato exterior"4 (Ibid.: 36). O movimento da saudade, contudo, não se limita à interioridade do sujeito. É preciso levar em conta seu aspecto transcendental. A alma saudosa é capaz de escrutinar os próprios limites e, ao mesmo tempo, alargar-se, buscando sensações e evocações de afetividade que são exteriores ao indivíduo.

Por essa vocação à transcendência, a saudade apresenta uma capacidade de possessão: "Não temos saudade, é a saudade que nos tem, que faz de nós seu objeto. Imersos nela, tornamo-nos outros. Todo nosso ser ancorado no presente fica, de súbito, ausente" (LOURENÇO, 1999: 32). O que a aproxima do transe: arrebatamento momentâneo, em que a noção de tempo e espaço se altera, como se interior e exterior se fundissem em uma única instância.

\section{Fotografia como suporte da saudade}

Toda fotografia é ausência e, portanto, saudade. Essa é a primeira aproximação que pode ser feita a partir dos apontamentos sobre as nuances do sentimento saudosista. A fotografia é projeção do referente deslocada para outro recorte espaço-temporal. O que um retrato mostra não existe mais como tal, já passou pelas transformações do tempo ou pode até mesmo nem mais existir. É nesse sentido que a imagem fixa é tomada como suporte da saudade, pois faz retornar aquilo que não mais existe com sua reencarnação imagética.

Cabe ressaltar, entretanto, a ambivalência da fotografia como artefato de culto à memória, quando atrelada à saudade. "Uma foto é tanto uma pseudo presença quanto uma prova de ausência”, afirma Susan Sontag (2004: 26). Essa constatação se relaciona com a ideia da dicotomia saudosista, segundo a qual, a saudade pode tanto evocar sentimentos de dor quanto de prazer. Para Dubois (1993: 81), a fotografia é uma "presença afirmando ausência" e, ao mesmo tempo, uma "ausência afirmando a presença". É essa relação ambivalente que movimenta e mistura emoções distintas no ato rememorativo, entre as quais se encontra a saudade.

Fotografia e saudade estabelecem uma relação muito próxima, principalmente pelo fato de a imagem fixa ter sido tomada socialmente como artefato da memória por excelência. É comum ao saudosista entregar-se à lembrança do passado, declarando paixão ao tempo idealizado no qual seus sentimentos encontram conforto.

Não é por acaso que os pequenos retratos de porcelana são fixados nas lápides de cemitério, muitas vezes ao lado de declarações de saudades eternas, ou de alguma frase que reforce a imortalidade do ente querido na memória familiar. São instâncias distintas, mas que se aproximam por sua evocação de presença e pelo afeto envolvido.

Nesse contexto, é possível afirmar que a fotografia - com todas as suas complexidades conceituais - estabelece relação bastante próxima com a saudade, tornando-se suporte ideal para que o indivíduo saudoso realize a transcendência necessária para reavivar simbolicamente a presença do ser amado que já não vive. 
Para Botelho (1990: 14), é justamente a saudade que possibilita a sobrevida da pessoa amada na imagem: "O poder evocativo da saudade é o único a atrair a transcendência da segunda realidade". Nesse sentido, a saudade é o que movimenta as emoções e alicerça o culto à memória dos que já foram. A fotografia, com sua promessa de eternidade, aplaca momentaneamente as saudades eternas da ausência deixada pela morte dos entes amados.

A fim de aprofundar a relação entre fotografia e saudade, propõe-se um exercício de reflexão baseado nas perdas, de modo a traçar conexões entre a ausência e o complexo sentimento saudosista.

\section{Perda I: o que se ama}

À fotografia foi atrelada a função de preservar fragmentos do visível, garantindo a perpetuação imagética dos feitos importantes nas diversas esferas sociais. Essa vocação memorialista está presente em outros usos dos registros fotográficos, mas é no reduto doméstico que os retratos se configuram como verdadeiros relicários afetivos, responsáveis por preservar a aparência dos acontecimentos e dos seres amados.

Dessa maneira, as fotografias dos encontros em família, os retratos de casamento ou da infância dos filhos são transformados em relicários afetivos, como explica Kossoy (2005: 42, grifo do autor): "todos nós guardamos fotos de nossas experiências de vida: imagens-relicário que preservam cristalizadas nossas memórias". Ainda segundo o autor, a fotografia produz um substituto portátil do sujeito ou cena fotografados, que podem, então, ser transportados através do espaço e do tempo. As cenas do mundo são transmutadas em imagens.

Ao que Kossoy (2005) denomina de imagem-relicário, Jean-Marie Schaeffer (1996) conceitua como foto-recordação, que não configura uma categoria de imagens, mas define a relação que se mantém com determinada imagem.

Ver uma foto-recordação é sentir-se, de imediato, em casa, independentemente das eventuais dificuldades que se possa ter em identificar de maneira concreta tal ou tal imagem em particular. Em outras palavras, o contexto perceptivo tem um papel crucial. (SCHAEFFER, 1996: 79)

A foto-recordação é capaz de suscitar lembranças e afetos naqueles que têm ligação direta com a imagem, o que mobiliza o sentimento de preservação das fotografias. É o que acontece, por exemplo, no caso dos retratos de família, que devem ser conservados cuidadosamente a fim de garantir a sobrevida imagética dos fragmentos do passado preservados na fotografia.

O registro fotográfico é tomado como duplo imagético, emanação direta do sujeito fotografado. $O$ que estabelece a confusa relação entre a imagem e seu referente, relação que é motivada pela "pulsão metonímica" (DUBOIS, 1993: 78, grifo do autor) advinda do caráter indicial da fotografia.

A imagem bidimensional é considerada parte do que foi fotografado. Com o desaparecimento do referente, o registro fotográfico é adotado como seu substituto. "É a foto que literalmente vai se tornar sua lembrança, substituir a ausência" (Ibid.: 90). Nesse sentido, a fotografia torna-se reaparição do referente em um jogo esquizofrênico, no qual, metonimicamente, a parte é recebida como o todo.

Essa sobrevida imagética é explicada conceitualmente por Kossoy (2009), quando afirma que a imagem fotográfica cria uma segunda realidade. A primeira realidade "é a realidade do assunto em si na dimensão da vida passada, diz respeito à história particular do assunto independentemente da representação" (Ibid.: 36). É a realidade própria dos fenômenos e, portanto, impossível de ser captada por um aparato técnico, conforme afirma Soulages (2010: 83): "o real é infotografável". 
Apesar de não poder captar a realidade exterior do mundo, a fotografia se apresenta como suporte ao que Kossoy (2009: 37) denomina de realidade interior, ou segunda realidade, isto é, a "realidade do assunto representado, contido nos limites bidimensionais da imagem fotográfica, não importando qual seja o suporte no qual esta imagem se encontre gravada".

A partir dessas definições, o autor deixa claro que a fotografia institui uma realidade própria, que mantém relação de contiguidade com o objeto fotografado, mas, ao mesmo tempo, instaura a representação que é própria da realidade interior da fotografia. "Inicia-se, portanto, uma outra realidade, a do documento: a segunda realidade, autônoma por excelência. Inicia-se um outro processo: o da vida do documento" (Id., 2012: 46, grifo do autor).

Ao criar essa segunda realidade, a fotografia garante a sobrevida imagética do que foi fotografado.

Os personagens retratados envelhecem e morrem, os cenários se modificam, se transfiguram e também desaparecem. O mesmo ocorre com os autores-fotógrafos e seus equipamentos. De todo o processo, somente a fotografia sobrevive, algumas vezes em seu artefato original, outras vezes apenas o registro visual reproduzido. (Ibid.: 168)

Essa segunda existência é menos instável do que a biológica. Mas, ainda assim, requer cuidados que garantam sua preservação. No caso das fotografias de família, a sobrevida é garantida pela relação afetiva e de culto, que assegura a existência e a manutenção dos registros fotográficos.

Conservar os retratos é resguardá-los de uma segunda morte. Kossoy (Ibid.: 168) destaca que o desaparecimento da segunda realidade, por ato voluntário ou involuntário, faz os personagens imortalizados simbolicamente pela fotografia morrerem outra vez. Ao comentar sobre a angústia de imaginar a destruição dos retratos de seus pais, Barthes (1984: 140) ilustra como se dá essa segunda morte simbólica:

Diante da única foto em que vejo um pai e minha mãe juntos, que sei que se amam, penso: é o amor como tesouro que desaparecerá para sempre; pois quando eu não estiver mais vivo ninguém poderá testemunhá-lo: não restará mais que a indiferente Natureza.

O desaparecimento da representação faz as lembranças se tornarem suscetíveis aos lampejos da memória e serem submetidas aos riscos do esquecimento.

\section{Perda II: o corpo da fotografia}

Em sua instância material, a fotografia doméstica foi tomada como artefato mnemônico: espécie de memória externa que dá estabilidade à dinâmica imprecisa dos processos memorativos, sedimentando na superfície do papel fotográfico a aparência daqueles ou daquilo que se deseja preservar. Artefato no sentido de suporte, de superfície palpável.

Além de ser artefato memorial, a fotografia também é envolta em uma aura afetiva, por sua capacidade de suscitar emoções e sentimentos. A partir dos velhos retratos, torna-se possível analisar a passagem dos dias, vasculhar na memória as sensações do tempo que se foi. A fotografia se apresenta como elo capaz de unir as pontas do passado em dado instante do presente. E isso se dá por sua vocação biográfica, como destaca Bosi (2003: 26): "Só o objeto biográfico é insubstituível: as coisas que envelhecem conosco nos dão a pacífica sensação de continuidade". 
O historiador Ulpiano Meneses (1998: 93) considera que os objetos, por sua materialidade, têm uma trajetória própria: "A biografia dos objetos introduz novo problema: a biografia das pessoas nos objetos". É a partir dessa interação entre o indivíduo e os artefatos que preserva ao longo da vida que se torna possível estabelecer processos memorativos, conforme destaca Marcus Dohmann (2013: 33):

Objetos ou coisas sempre remetem a lembrança de pessoas ou lugares, de uma simples fotografia até um marco arquitetural. Ao proporcionar a conexão com o mundo, os objetos mostram-se companheiros emocionais e intelectuais que sustentam memórias, relacionamentos e histórias, além de provocarem constantemente novas ideias.

A materialidade possibilita que a fotografia seja tomada como lugar de memória. Segundo o historiador Pierre Nora (1993: 13), os lugares de memória "nascem e vivem do sentimento que não há memória espontânea, que é preciso criar arquivos, que é preciso manter aniversários, organizar celebrações, pronunciar elogios fúnebres, notariar atas, porque essas operações não são naturais". Dessa forma, a capacidade memorativa torna-se dependente dos artefatos que são adotados como recursos para dar estabilidade às lembranças.

A fotografia, em sua instância material, é muitas vezes tomada como segundo corpo dos ausentes, a aplacar a saudade a partir da visualização dos antigos retratos. Com o advento da fotografia digital, tem-se outra perda: a do próprio corpo bidimensional, suporte material da imagem. Esta torna-se um espectro, sem superfície palpável, e que tem a potencialidade de aparecer nas inúmeras telas. Imagem errante, aparição luminosa de códigos informáticos. Assim, a fotografia que já se configurava como o suporte imagético mais difundido, passou a ser radicalmente ubíqua.

As práticas analógicas necessitavam de suporte material em todo o processo. A fotografia digital subverte isso e se apresenta pronta. A priori, não é necessária nenhuma ação além do clique para que ela exista. $O$ trabalho do laboratorista foi substituído pelo rápido processamento informático, que transforma a luz em códigos binários, mosaico de pixels decodificados por programas.

A imagem digital existe em sua inexistência palpável. Perda de materialidade que firma outro regime de visualidade, marcado pela produção exacerbada. Registros que já não têm a mesma importância de preservação à qual eram submetidas as fotografias de família, por exemplo, mas que estabelecem novas dinâmicas e processos comunicativos.

Segurar um retrato não é o mesmo que visualizar a projeção em uma tela. A própria ação do tempo sobre o papel, que amarelece e desbota, encarrega-se de acrescentar certa dramaticidade aos registros analógicos. As imagens digitais, por sua vez, mantêm-se intocáveis, literalmente. Sem o suporte material, as fotografias perdem a dimensão do tato, do cheiro de coisa guardada, aspectos que se somavam ao suporte visual na evocação de lembranças.

A digitalização significa, em muitos casos, a perda do domínio sobre o acervo fotográfico. Por mais que a observação do álbum se desse em momentos específicos, envolvendo na maioria das vezes uma situação ritualística, a segurança da propriedade garantia o conforto da preservação. Agora, com a transmissão da posse para instâncias externas à família - como no caso das redes virtuais e plataformas de arquivamento on-line -, o medo do apagamento e da destruição dos artefatos visuais da memória é um espectro que ronda a sociedade contemporânea, ainda que essa reflexão não seja efetiva.

Os mais saudosos - ou temerosos - ainda imprimem as fotografias, como forma de materializar os pixels no papel, dando corpo à imagem. Essa prática, no entanto, não é a mais usual. Na maioria das vezes, os registros são preservados apenas em sua instância virtual. 


\section{Perda III: a memória}

A perda do corpo da fotografia marca ainda a facilidade de produção exacerbada pelos dispositivos móveis conectados à internet. Com um mesmo aparelho é possível fotografar, editar e divulgar os registros nas inúmeras redes da Internet. Os prenúncios de Vilem Flusser (2009: 54) parecem ter se concretizado: "a mania fotográfica resulta em torrente de fotografias. Uma torrente-memória que é fixa. Eterniza a automaticidade de quem fotografa".

O excesso de registros estabelece um regime de hiperdocumentação, que não só atesta a natureza fóbica da sociedade contemporânea - que necessita sentir que está vivendo todo o tempo o tempo todo - como proporciona a terceira perda, aqui apresentada como hipótese: a do papel de preservação da memória atribuído à fotografia.

O daguerreótipo, primeira experiência fotográfica comercial, tinha valor social de artigo de luxo. A pequena placa espelhada apresentava a imagem nítida e com detalhes precisos do objeto ou sujeito fotografado. Imagem estável, com fixação de longa duração. Os primeiros daguerreótipos preservam ainda hoje as cenas eternizadas nos sais de prata. A confiabilidade atribuída à fotografia fez com que logo fosse adotada como instrumento de perpetuação dos ritos de passagem e, posteriormente, das cenas do cotidiano.

Ao observar as transformações técnicas, estéticas e sociais da fotografia, a exemplo da transição dos registros domésticos dos álbuns de família para as redes virtuais da internet, é possível apreender que seu uso como artefato de preservação tem enfraquecido. Novas práticas ganham destaque e parecem estabelecer outros regimes para a história da fotografia, agora marcada pelo rápido descarte e pela perecibilidade dos registros visuais.

As demandas sociais instituem que urge viver o agora, o instante efêmero. Quando tudo é imediato, não é preciso conservar o passado, muito menos preservar fragmentos para o futuro. Nesse contexto, os registros fotográficos estão se tornando cada vez mais descartáveis. Gradativamente, a anamnese dá lugar à dismnésia, ou seja, ao enfraquecimento da memória.

Em vez de fomentar a recordação, o excesso de registros parece desencadear o efeito oposto, culminando no esquecimento. Quando tudo é fotografável, não é mais necessário preservar os registros, pois esses logo serão substituídos por novas fotografias, igualmente perecíveis. O que acarreta a inversão radical no sentido atribuído ao ato fotográfico, como observa Joan Fontcuberta (2012: 30): "achávamos que alguma coisa do referente se incrustava na fotografia; pois agora devemos pensar o contrário: há algo da fotografia que se incrusta no referente".

Isso não significa, contudo, que houve uma mudança ontológica da fotografia. Os registros da câmera escura ainda continuam com a atribuição basilar de preservar fragmentos do visível como imagem fixa. O que mudou foi a sociedade, que agora utiliza a fotografia também para outros usos, marcados pela obsolescência. Com tanto excedente de produção, as fotografias se tornaram ordinárias e menos memoráveis, ou seja, foram afetadas em sua capacidade de suscitar recordações.

\section{Das perdas às saudades}

Susan Sontag (2004) considera a fotografia como uma arte elegíaca, marcada pela melancolia e pelo saudosismo. Se antes a relação da perda do referente-em especial os entes queridos levados pela morte - fazia os retratos serem tomados como suporte da saudade, ao perder a materialidade, a fotografia apresenta-se como emblema da própria perda, que deixa como saudade um ideal fotográfico que não mais existe. Tem-se, desse modo, também a perda da vocação mnemônica atribuída à fotografia.

Paradoxalmente, em vez de enfraquecer as potencialidades elegíacas da imagem fotográfica, tais perdas parecem fortalecer a instância saudosista. A fotografia passa a carregar no próprio cerne histórias e lembranças do que um dia foi. 
Assim, diante dos vários prenúncios de morte, a fotografia - com sua ambivalência intrínseca - encontra outras configurações para existir, tirando das perdas a força para continuar. Nesse contexto, em vez de fazer afirmações, parece mais sensato levantar um questionamento, ainda que retórico: quantas saudades cabem em uma fotografia?

\section{Referências}

BARTHES, R. A câmara clara: notas sobre a fotografia. Rio de Janeiro: Nova Fronteira, 1984.

BOSI, E. O tempo vivo da memória: ensaios de psicologia social. São Paulo: Ateliê Editorial, 2003.

BOTELHO, A. Da saudade ao saudosismo. Lisboa: Ministério da Educação, Instituto de Cultura e Língua Portuguesa, 1990.

DAMATTA, R. Antropologia da saudade. In: Conta de mentiroso: sete ensaios de antropologia brasileira. Rio de Janeiro: Rocco, 1993. p. 17-34.

DOHMANN, M. A experiência material: a cultura do objeto. In: (Org.). A experiência material: a cultura do objeto. Rio de Janeiro: Rio Books, 2013. p. 31-46.

DUBOIS, P. O ato fotográfico. 13. ed. Campinas: Papirus, 1993.

FLUSSER, V. Filosofia da caixa preta: ensaios para uma futura filosofia da fotografia. Rio de Janeiro: Relume Dumará, 2009.

FONTCUBERTA, J. A câmera de Pandora: a fotografia depois da fotografia. São Paulo: Gustavo Gili, 2012.

KOSSOY, B. Fotografia \& História. São Paulo: Ateliê Editorial, 2012. 2009. Realidades e ficções na trama fotográfica. 4. ed. São Paulo: Ateliê Editorial, Fotografia e memória: reconstituição por meio da fotografia. In.: ETIENNE, S. (Org.). O fotográfico. 2. ed. São Paulo: Hucitec; Senac, 2005. p. 39-46.

LOURENÇO, E. Mitologia da saudade: seguido de Portugal como destino. São Paulo: Companhia das Letras, 1999.

MENESES, U. T. B. Memória e cultura material: documentos pessoais no espaço público. Estudos Históricos, Rio de Janeiro, v. 11, n. 21, p. 89-103, 1998. Disponível em: <https://goo.gl/hkQ9pV>. Acesso em: 15 jun. 2017.

NORA, P. Entre memória e história: a problemática dos lugares. Projeto História, São Paulo, n. 10, p. 7-28, 1993. Disponível em: <https://goo.gl/w4cr7Y>. Acesso em: 03 jun. 2017.

PIÑEIRO, R. Filosofía da saudade. Vigo: Galáxia, 1984.

SCHAEFFER, J.-M. A imagem precária: sobre o dispositivo fotográfico. Campinas: Papirus, 1996.

SILVA, M. O. Saudades eternas: a fotografia no limiar entre a morte e a eternidade. 2016. Dissertação (Mestrado em Comunicação) - Universidade Estadual de Londrina, Londrina, 2016. Disponível em: <https://goo.gl/skVQPj>. Acesso em: 5 de jun. 2017.

SONTAG, S. Sobre fotografia. São Paulo: Companhia das Letras, 2004. 
SOULAGES, F. Estética da fotografia: perda e permanência. São Paulo: Senac, 2010.

VAZ, R. S. Entrevista a Michel de Oliveira Silva. Londrina, 28 jul. 2015. (123'53"): gravação em áudio. 